\title{
REGIÃO E ESCALA REGIONAL: OS IMPASSES PARA A IMPLEMENTAÇÃO DE POLÍTICAS REGIONAIS NO BRASIL ATUAL ${ }^{1}$
}

\author{
ADAUTO GOMES BARBOSA ${ }^{2}$ \\ Universidade Federal de Pernambuco
}

\section{Introdução}

O presente artigo discute a região, em termos teórico-conceituais, sob o ponto de vista da Geografia, apontando alguns elementos de distintas abordagens. Também aborda a perda de visibilidade da escala regional em tempos recentes e critica a ideologia neoliberal que preconiza o Estado mínimo, o qual dá maior visibilidade às escalas global e local, em detrimento da escala nacional e das políticas regionais.

Nesse sentido, o artigo chama a atenção para a abordagem multiescalar e destaca a importância da escala regional na implementação de políticas públicas em meio ao movimento atual de globalização em que o Brasil está inserido. Faz, ainda, alguns esclarecimentos em termos conceituais para a natureza explícita e implícita das políticas regionais, diferencia política regional de política territorial, política regional de política social, além de explicitar a concepção de desenvolvimento aqui adotada.

As políticas regionais têm encontrado muitos entraves no Brasil desde o agravamento da crise econômica nos anos 1980. Na década

${ }^{1}$ Artigo produzido a partir das leituras e discussões promovidas no âmbito da disciplina Análise Regional e Políticas Regionais, ministrada pelos professores doutores Tânia Bacelar de Araújo e Jean Bitoun, do PPGEO / UFPE, aos quais se agradece pela inestimável contribuição.

${ }^{2}$ Doutorando do Programa de Pós-Graduação em Geografia da Universidade Federal de Pernambuco. 
seguinte, o novo contexto caracterizado pela abertura da economia, pela reestruturação produtiva, pela estabilização monetária e pela crescente inserção do Brasil na economia global também se constituíram em dificuldades para o planejamento e implementação de políticas regionais no Brasil.

A transformação dos municípios como entes da Federação pela Constituição de 1988 e a crise e extinção dos órgãos estatais de planejamento regional, como a SUDENE e a SUDAM, também se colocam como obstáculos para a formulação e implementação de políticas de desenvolvimento urbano e regional. Além desses elementos, a falta de uma representatividade própria das regiões metropolitanas e das macrorregiões também tem contribuído para engessar as possibilidades do planejamento e implementação de políticas ao nível da escala regional.

A dinâmica urbana e regional brasileira, em função das transformações acima assinaladas, tornou-se mais complexa e não mais se caracteriza pelos processos de concentração e desconcentração regional do período de 1930 a 1985 . A despeito dessa complexidade, não houve grande alteração na divisão territorial do trabalho nos tempos recentes (Brandão, 2004). O que se verifica é a persistência de uma região mais dinâmica, de outra que continua deprimida em termos econômicos e há também variados núcleos geográficos que apresentam especializações regionais, configurando áreas de inovação mais recentes.

Se as especificidades da formação sócio-histórica de cada região colocam-se como certo entrave ou resistência à tendência globalizante e homogeneizadora, esse obstáculo deve ser relativizado. Afinal, "[...] apesar da unificação crescente dos mercados e da globalização de uma economia capitalista de padrão neoliberal, a diferenciação espacial e, mais ainda, a re-produção das desigualdades, é um fenômeno crescente." (Haesbaert, 2005:7).

A globalização tanto promove homogeneização espacial, como, contraditoriamente, gera a fragmentação e a diferenciação regional. Nestes termos, Haesbaert (2005) considera que se pode até pensar a região como produto da globalização. Ele ainda destaca que a diferenciação geográfica e cultural deixa de ser um entrave para a atuação do capital, podendo, inclusive, converter-se num diferencial a seu favor. 
Não se pode perder de vista nesse processo de globalização o duplo movimento na produção do espaço configurado pelas verticalidades e horizontalidades (Santos, 1997). As ações verticais correspondem à atuação dos chamados agentes hegemônicos da globalização, os quais são exógenos ao lugar e, ao serem implantadas, instauram uma nova ordem e, em certa medida, impõem uma desordem em relação às tradições e à economia local. As horizontalidades são endógenas ao lugar e são geradoras de complementaridades e cooperação. Assim, as horizontalidades configuram forças oriundas do lugar e contrapõem-se às tendências verticalizantes.

Faz-se necessário aqui ressaltar que os termos lugar e local não são sinônimos e nem sempre referem-se ao mesmo contexto de análise do espaço. No sentido abordado por Santos (2008), o lugar pode ser tanto uma pequena porção de um território, uma região de um país ou ainda todo o Estado-nação.

De acordo com Milton Santos, o que funda o lugar é a unicidade e a contiguidade dos eventos. O lugar pode ser compreendido como "a extensão do acontecer homogêneo ou solidário e é pelo Lugar que revemos o Mundo e ajustamos nossa interpretação, pois, nele, o recôndito, o permanente, o real triunfam, afinal, sobre o movimento, o passageiro, o imposto de fora" (Santos, 1997, p. 37). Enquanto o termo lugar é o locus de reprodução das relações do cotidiano, o uso que aqui se faz do termo local remete-se a um recorte espacial específico, sendo, pois, um nível escalar para estudar o espaço geográfico.

Para discorrer sobre a questão urbana e regional, o texto faz uma breve discussão sobre a trajetória do conceito de região à luz da ciência geográfica. Em seguida, trata da relação global / local e o que certamente poderia considerar-se como o enfraquecimento das políticas regionais. Mais adiante, aborda as tipologias, alcances e possibilidades atuais dessas políticas. A contribuição que se pretende dar aqui é de fazer algumas reflexões sobre as políticas regionais no contexto atual do Brasil e, ao mesmo tempo, instigar o leitor para a necessidade de aprofundar esse debate. Espera-se que tal propósito seja alcançado. 


\section{Breve abordagem teórica sobre o conceito de região}

A região sempre se constituiu como um dos conceitos-chave da Geografia e tem grande recorrência em várias outras disciplinas, mormente às que se voltam para o debate do desenvolvimento regional. A despeito disso, o conceito de região ora ganha, ora perde visibilidade nos debates acadêmicos.

As matrizes teóricas desse conceito em Geografia remontam desde os gregos, na Antiguidade Clássica, até a obra de Bernard Varenius, no século XVIII. Em termos gerais, pode-se dizer que duas perspectivas geográficas são identificadas: uma geral e outra especial. Trata-se da velha dicotomia expressa nas perspectivas nomotética (geral) e idiográfica (regional). A Geografia Regional, com lado pragmático, também estaria associada aos processos de regionalização, ação por excelência do Estado para organizar sua base territorial com vistas às políticas públicas.

Elevada ao posto de paradigma, a Geografia Regional clássica tinha forte tradição francesa e perdurou até meados do século passado. Essa tradição também prosperou noutras "escolas", a exemplo dos Estados Unidos, com os estudos culturais de Carl Sauer. "Daí o fato da região ter se transformado naquilo que poderíamos conceber como o conceito mais pretensioso da Geografia, 'síntese' dos múltiplos condicionantes que compõem o espaço geográfico [...]” (Haesbaert, 2005, p. 10).

Em meados do século passado, o advento da chamada Geografia Quantitativa, apoiada em bases neopositivistas, resultou no abandono da concepção clássica de região e passou a considerá-la como um recorte espacial demarcado por classificação de áreas. Para Haesbaert (2005), a região como classificação de área representa uma grande simplificação do conceito regional, pois assenta-se num pragmatismo estatal ou empresarial, que desconsidera aspectos relevantes do fenômeno regional, como o processo histórico de constituição da região.

Outra vertente da mesma perspectiva neopositivista é a que vincula a região ao funcionalismo. A partir daí, as regiões funcionais emergiram no mesmo contexto em que ganhou visibilidade a teoria dos lugares centrais, de Walter Christaller, segundo a qual um centro polarizador exerce influência por um raio, configurando seu espaço regional. 
A perspectiva marxista também repercutiu nas teorizações sobre o fenômeno regional. Apesar de a divisão internacional do trabalho estabelecer-se num processo de reprodução do capital, que ocorre de forma desigual e combinada, economistas marxistas, como Francisco de Oliveira, chegaram a ressaltar que a existência do fenômeno regional estaria sendo posta em xeque, ao propor que:
num sistema econômico de base capitalista, existe uma tendência para a completa homogeneização da reprodução do capital e de suas formas, sob a égide do processo de concentração e centralização do capital, que acabaria por fazer desaparecer as "regiões" [...] (Oliveira, 1981, p. 27)

É importante notar que o autor trata muito mais de uma tendência conforme grifado por ele - do que propriamente do fim da região e que não se deve considerar que o processo de reprodução do capital ocorre uniformemente no espaço mundial. Reforçando esse argumento, ele afirma que as áreas que estiveram sob o domínio do capitalismo mercantil não apresentam logicamente a mesma tendência de uniformização, o que se verifica no território dos Estados Unidos.

Portanto, a despeito da refutação da região em sentido clássico, enquanto estudo do particular e do específico, os marxistas admitem o fenômeno regional como estando associado aos determinantes econômicos e políticos da produção do espaço, sob a perspectiva teórico-metodológica da divisão territorial do trabalho.

Diante das inúmeras críticas e juízos de que a região estaria desaparecendo em meio à globalização, o geógrafo Milton Santos advoga a "universalidade atual do fenômeno da região". Para esse autor, à medida que a globalização consolida-se, e com ela cresce a tendência à uniformização dos territórios, pela via econômica, política, cultural etc, mais acentuado também se torna o processo de diferenciação dos lugares. Assim, a globalização é geradora tanto de uniformização quanto de diferenciação e de fragmentação. Para o autor, a expansão do capital hegemônico não eliminou as diferenciações regionais, mas, ao contrário, as intensificou. De acordo com suas próprias palavras: 
[...] já que o espaço se torna mundial, o ecúmeno se redefine, com a extensão a todo ele do fenômeno de região. As regiões são o suporte e a condição de relações globais que de outra forma não se realizariam. Agora, exatamente, é que não se pode deixar de considerar a região, ainda que a reconheçamos como um espaço de conveniência e mesmo que a chamemos por outro nome. (Santos, 1997, p. 196)

Se a concepção clássica admitia que a região representava um edifício duradouro e, até em muitos casos, delimitado com base nos elementos naturais considerados mais estáveis, atualmente, a região deixa de ser uma construção estável. A ampliação da divisão internacional do trabalho e o aumento do comércio mundial ocorrem de forma paralela à aceleração dos fluxos e das mudanças do conteúdo das regiões. Nesse sentido, o referido autor reitera que "[...] o que faz a região não é a longevidade do edifício, mas a coerência funcional, que a distingue de outras entidades, vizinhas ou não. $\mathrm{O}$ fato de ter vida curta não muda a definição do recorte territorial." (Santos, 1997, p. 197).

Por sua vez, a abordagem neomarxista analisada por Haesbaert (2005; 2010) indica importantes caminhos para se pensar o fenômeno regional no contexto atual. Trata-se de uma perspectiva de análise mais aberta, no sentido de que coloca em xeque a concepção tradicional de região como classe de área ou ainda como recorte espacial contínuo, possuidor de uniformidade interna. Mais do que voltar-se para a questão da suposta igualdade interna, o novo entendimento de região não perde de vista as inúmeras diferenças externas. Em decorrência da extrema complexidade do espaço geográfico atual, a região torna-se cada vez mais descontínua, apresentando "buracos" (Allen et al., 1998). Esses buracos significam que o fator proximidade espacial não é mais o indicador primordial de geração da coesão interna da região.

Há ainda a possibilidade de se pensar a região sob a perspectiva reticular, pois a economia globalizada estabelece-se no espaço em redes. A região, formando uma mancha contínua, permanece, mas não é a única forma. Considerando o paradigma informacional propugnado por Castells (1999), o espaço geográfico do mundo atual configura o espaço de fluxos, 
o qual apresenta muito mais uma relação de complementaridade do que propriamente de contraposição ao espaço dos lugares.

Também não se pode deixar de considerar a estruturação da região tendo por base a integração de grandes áreas metropolitanas com as áreas industriais próximas, configurando uma cidade-região, tal como ocorre com a Região Metropolitana de São Paulo e as mesorregiões de Campinas, São José dos Campos, Sorocaba e Santos (Diniz e Campolina, 2007).

Nessa linha de raciocínio, o que funda a cidade-região são os fluxos internos e a integração entre os seus núcleos urbanos a partir da produção industrial que, no exemplo citado da cidade-região paulista, acompanha os eixos formados pelas principais rodovias. A produção e o uso de ciência e tecnologia também determinam a configuração da cidade-região pelas áreas industriais que a compõem.

Outro ponto para reflexão são os complexos de alta tecnologia baseados numa crescente e contínua produção de inovações, conforme o caso dos clusters de alta tecnologia, como a região de Sophia-Antipolis, na França, e o Vale do Silício, nos Estados Unidos, promovendo uma reestruturação do espaço para além do território nacional (Tavares, 1997). Essas regiões são polarizadas por tecnopolos e seu poder de influência pode alcançar praticamente todo o mundo por conta das tecnologias desenvolvidas nesses espaços, imprescindíveis para a economia mundial.

Segundo Haesbaert (2005), pode-se pensar a região também sob o prisma das representações, envolvendo a análise do discurso e a identidade. Nesse sentido, a elaboração de um discurso na mídia criando uma imagem positiva de uma determinada área pode constituir-se num importante instrumento para atrair novos investimentos econômicos e, ao mesmo tempo, atender às estratégias do Estado e de empresas, no intuito de fortalecer a identidade regional.

Tomando por base a análise do discurso, uma região pode ser inventada ou reinventada, conforme tese defendida por Albuquerque Júnior (2001). Para esse autor, há uma construção da ideia de Nordeste, referindose a essa região brasileira a partir de práticas discursivas que instituem e fazem valer essa região das primeiras décadas do século passado até os 
dias de hoje. A filiação teórico-metodológica do autor em contexto é a do pós-estruturalismo. Sob tal ponto de vista, há uma ruptura com a:

estabilidade e o fundamento das grandes estruturas,
provavelmente (...) sintetizada através de expressões como
"multiplicidade", (e/ou diferença), "nomadismo" (ou
mobilidade e fluidez) e "devir" (ou criação do efetivamente
novo), elementos-chave e às vezes até sobrevalorizados no
posicionamento filosófico de alguns autores. (Haesbaert,
2010, p. 64)

À luz desse posicionamento teórico-metodológico, Durval Albuquerque Júnior entende que o Nordeste brasileiro constitui uma invenção moldada a partir de um discurso que elabora uma imagem do que atualmente se concebe como tal.

\begin{abstract}
A região se institui, paulatinamente, por meio de práticas e discursos, imagens e textos que podem ter ou não, relação entre si, um não representa o outro. A verdade sobre a região é constituída a partir dessa batalha entre o visível e o dizível. O que emerge como visibilidade regional não é representado, mas construído com ajuda do dizível ou contra ele. [...] Nem sempre o enunciável se torna prática e nem toda prática é transformada em discurso. Os discursos fazem ver, embora possam fazer ver algo diferente do que dizem. (Albuquerque Júnior, 2001, apud Haesbaert, 2010, p. 69)
\end{abstract}

O autor em contexto não está preocupado com as bases materiais em que se configura o espaço geográfico da região, mas, sobretudo, com sua invenção simbólica num contexto histórico determinado. Sua tese desfaz o Nordeste como uma região "natural" e a vê como produto do discurso regionalista que inventa o Nordeste e também inventa o nordestino como sujeito histórico e social. Nesses termos, a imagem dominante que atualmente se tem de ambos (o Nordeste e o nordestino) é fruto dessa construção / invenção social e histórica. Tal posicionamento ressalta a importância de ter clareza para as várias possibilidades de como a institucionalização do fenômeno regional se dá e de que a região nem sempre é criada a partir de elementos objetivos. 
Do que foi discutido até aqui, é importante frisar que, no processo de análise regional, seja feito um estudo da história da região objeto de análise, procurando identificar os agentes que produziram e os que produzem o seu espaço, quais são suas forças atuantes em termos políticos, econômicos e sociais. Dependendo da região, esses agentes podem ser apenas locais ou ter alcance global, caso a economia local esteja inserida nos fluxos da economia globalizada. A história da região não é simplesmente anulada, como se a região não tivesse uma espessura histórica e cultural. Mas se de um lado e como já foi dito, a diferenciação regional parece resistir ao processo globalizador-homogeneizador, por outro, conforme reitera Haesbaert (2005), baseado em R. Robertson, a diversidade coloca-se como um "produto vendável" ao capitalismo e a região, sob esse aspecto, constituiria produto do próprio capitalismo.

\section{O global e o local em face da abordagem regional e da ação do Estado}

Desde a década de 1980 e com maior força nas duas décadas seguintes, têm sido privilegiadas as análises de âmbito global e local. Tal constatação verifica-se em várias ciências humanas, a exemplo dos estudos da Economia, da Ciência Política, da Geografia, dentre outras disciplinas. $\mathrm{O}$ quadro real em que tal evidência se dá parece muito claro. Questões como os problemas ambientais globais e locais, as crises financeiras e o terrorismo internacional são bons exemplos de como muitos problemas do mundo atual repercutem global e localmente. Isso é fato inconteste.

Assim, ao afetar o cotidiano de cidades e exigir novas medidas na rotina dos procedimentos de segurança em aeroportos, ou ainda o aumento exponencial dos fluxos financeiros e informacionais, que podem abalar a economia mundial, esses problemas exigem uma abordagem nos âmbitos global e local.

Também é incontestável que o mundo atual torna-se mais integrado graças às inovações das tecnologias de transporte e comunicações, rompendo distâncias e redimensionando o que se entende como próximo ou distante, lento ou acelerado. Empresas transnacionais atuam em dezenas de países e, à distância, comandam seus negócios como se atuassem apenas 
nesse ou naquele lugar. O resultado disso é que muitos problemas locais têm origem exógena e derivam de forças que se projetam globalmente.

Afirmar que os eventos acima se manifestam local e globalmente não é suficiente para compreender a sua dimensão espacial. Por outro lado, quando se busca a sua apreensão numa escala regional, é preciso dizer que não há apenas uma escala regional, mas várias escalas regionais.

Tomando-se por base o Brasil, as macrorregiões, como sugere o próprio nome, são muito grandes e, na maioria das vezes, pouco adequadas para se pensar uma política pública regional. Há outros recortes espaciais que permitem enxergar e enfrentar os problemas mais de perto, como as mesorregiões, os "Territórios da Cidadania" do Ministério do Desenvolvimento Agrário, os arranjos produtivos locais etc. Se se parte do raciocínio de que o regional constitui o intermediário entre o global e o local, deve-se considerar, também, que a escala regional não é algo rígido de cunho universalizante.

Nesse sentido, são identificadas tantas escalas regionais quanto maior for a densidade do território em termos de seu conteúdo técnico, econômico, social e natural. Os possíveis impactos de um problema ambiental certamente não é o mesmo para um vasto território, como uma macrorregião do IBGE e, nesse caso, é preciso que a política pública considere todas as suas particularidades e implicações espaciais. Inclusive, igualmente necessário é considerar que, em certo contexto, conforme apontado por Albuquerque Júnior (2001), a região configura uma construção social e histórica, e a política regional nesse sentido precisa levar em conta o papel dos seus atores social e historicamente constituídos.

Há nisso tudo uma questão de fundo, que é a crise do conceito de região e, na sua esteira, uma crise das políticas ditas regionais, sobretudo em países de grande extensão territorial. Portanto, ao invés de falar em uma crise da escala regional, o centro do problema estaria numa crise da região. Sobre este assunto, sugere-se a leitura de Haesbaert (2005), que faz importantes reflexões sobre "a morte e a ressurreição da região" ao longo história da Geografia Regional.

A região como recurso analítico deve servir de base para a formulação das políticas regionais. Contudo, as divisões regionais oficiais configuram limites político-administrativos e não se colocam como recurso analítico de reflexões e estudos mais profícuos para compreender a 
complexidade regional. Daí a necessidade de levar em conta as diversas escalas regionais, identificando, de acordo com o problema, qual é a mais adequada. Igualmente necessário é compreender a concepção de Estado que preside as políticas públicas regionais e nacionais. Essa tarefa é certamente uma contribuição da academia, apresentando caminhos e possibilidades de enfrentamento dos problemas regionais. Os parágrafos a seguir apontam algumas reflexões nessa perspectiva.

Araújo (2000), em artigo que discute os dilemas e possibilidades do desenvolvimento brasileiro, destaca que, em razão da hegemonia da visão neoliberal, há "a consolidação de uma visão que é ideológica e política: a visão de "quanto menos Estado e quanto mais mercado, melhor; quanto mais indivíduo e quanto menos coletividade, melhor"' (Araújo, 2000, p. 269 , grifo da autora).

Ora, é o Estado o principal indutor e promotor de políticas regionais e nacionais. No momento em que ele é colocado como entrave, passa a ser deliberadamente enfraquecido, ganhando força a tese do Estado mínimo. Não por acaso, há um fortalecimento das ações no nível local e, no global, um enfraquecimento da escala regional.

Esse enfraquecimento das políticas regionais é parte de um processo maior em que o Brasil foi inserido a partir da década de 1990, conforme já exposto, no qual o Estado passou a ser encarado como inimigo e obstáculo ao livre mercado. Para a autora,

\section{[...] o capital, agora, quer circular na esfera global. [...] Quanto menos regulação nacional, tanto melhor. Quanto mais flexibilização e desregulamentação, tanto melhor para os atores que esperam no espaço mundial. E, quanto mais uniformização, nesse espaço, melhor ainda. Os Estados nacionais estão, de fato, contestados pela dinâmica da economia. (Araújo, 2000, p. 269)}

Em outros termos, é o Estado quem regula e, para o capital, quanto menos regulação melhor, mais capacidade ele tem de reproduzir-se porque menor tende a ser a transferência e a distribuição mais efetiva da riqueza para os segmentos sociais mais carentes e para as regiões menos favorecidas econômica e tecnologicamente. A escala regional perde visibilidade porque o capital age de forma bastante seletiva e está muito 
mais disposto a atuar em recortes territoriais onde terá maior retorno do que investir em áreas menos equipadas em infraestruturas e mercado de consumo. O Estado passa a estimular muito mais as políticas geradoras de competitividade regional do que as políticas geradoras de coesão regional. A consequência disso é o aprofundamento do fosso existente entre as regiões mais ricas e as mais pobres.

O problema essencial é que no período atual de acentuada crise fiscal, o Estado dispõe de poucas condições para grandes investimentos em políticas regionais. Essas precisam ser efetivamente geradoras de coesão do espaço nacional e, sob tal perspectiva, são essenciais para a construção de um sólido projeto de nação. A seletividade espacial, estabelecida pelos mecanismos de mercado, não resolve as desigualdades regionais, ao contrário, aprofunda-as. Daí o papel proeminente do Estado e a necessidade de o mesmo ser colocado como elemento indutor de políticas regionais.

Reforçando tal preocupação, Brandão (2004) advoga a pertinência de se pensar alternativas para o desenvolvimento urbano e regional a partir do enfoque teórico-metodológico da divisão social do trabalho, sem perder de vista que a reprodução do capital gera uma divisão territorial do trabalho no nível internacional. Ele discute a globalização tomando por base as escalas de análise e ressalta que não há escalas "ótimas", lançando forte crítica aos localistas.

No mundo atual, o capital reproduz-se usando diversas escalas e, como se sabe, a escala está associada à capacidade de atuação dos capitais. Para ele, há uma ideia equivocada de que, sob o fito do território, tudo se explica e resolve no plano local.

A necessidade da "territorialização" das intervenções públicas é tomada como panaceia para todos os problemas do desenvolvimento. Assevera-se, de forma velada ou explícita, que todos os atores sociais, econômicos e políticos estão cada vez mais plasmados "diluídos" (subsumidos), em um determinado recorte territorial. Na verdade, parece existir uma opção por substituir o Estado ("que se foi") por uma nova condensação de forças sociais e políticas (abstrata) que passa a ser chamada de território. (Brandão, 2004:58.) 
É bom que se ressalte que a crítica do autor acima não é ao território em si como conceito analítico, mas ao uso desse conceito numa perspectiva demasiadamente localista. Ele defende que a questão central é a discussão do processo de desenvolvimento-subdesenvolvimento, e não os problemas na escala estritamente local. Brandão assenta-se no campo da análise política e entende que é importante fortalecer o papel do Estado. Nesse sentido, defende a análise regional por meio de uma abordagem multiescalar, ou seja, ficando atento aos processos que operam em múltiplas escalas. O local, em inúmeros casos, está imbricado com o global e vice-versa. Daí a conclusão de que a análise regional é fundamental.

Entretanto, o autor tece severa crítica ao localismo, pois há que se ter o cuidado para o fato de que nem sempre é possível encontrar relações e imbricações entre local e o global. Segundo ele, o território (ou a escala local se preferir) torna-se uma panaceia, sendo reificado, fetichizado, personificado, quando tudo forçosamente passa a ser explicado pela escala local.

Seguindo ponto de vista semelhante, Becker também faz uma apreciação desse quadro de referência com foco na análise política e, portanto, defende a necessidade de fortalecimento do Estado nacional por meio da gestão do território nacional. Para a autora, há uma tensão no Brasil atual, marcada por um duplo processo que alcança a escala global: a revolução científica e tecnológica, e a crise ambiental. No primeiro caso, fica evidente que o grande desafio do Brasil é inserir-se na economia da informação e do conhecimento e, no segundo, a questão ambiental é vista como provável grande restrição para a expansão do capitalismo, sob formas convencionais de produção.

Outro elemento da globalização discutido pela autora em contexto é o processo de financeirização do capital, gerador de total desprendimento do setor financeiro em relação ao setor produtivo. Esse quadro tornou o Estado nacional impotente para estabelecer a governabilidade do seu próprio território, uma vez que:

Os conflitos não podem mais ser resolvidos apenas entre Estados. São necessários informação, negociação e barganha junto a empresas e instituições financeiras globalizadas. Mas, ainda é relevante o papel dos Estados, cuja diferenciação 
orienta os fluxos e que respondem de formas muito diversas à globalização. (Becker, 2010:36)

Fica claro, dessa forma, que a autora encara o Estado como instância fundamental. Ela defende uma abordagem multiescalar, destacando a importância de implementação de políticas direcionadas para o patrimônio natural do território brasileiro, sem desconsiderar o saber local e entendendo que a questão ambiental faz parte da geopolítica global. Em linhas gerais, vê-se que a questão regional amazônica não está desvinculada da ordem ambiental e econômica global, ao mesmo tempo em que cabe ao Estado brasileiro (portanto à escala nacional) a missão de elaborar e executar políticas regionais que não deixem de lado a escala local. É nesse cruzamento de escalas geográficas que deve residir a atuação do Estado nacional.

Retomando Araújo, a autora afirma que a globalização impõe um padrão de competitividade e "carrega, em si, a tendência à homogeneização e ela entra em conflito com aquilo que tem caráter local, porque o local encarna o que é próprio, o que é particular, o que é diferente" (Araújo, 2000, p. 276). Nesse sentido, os lugares são distintos não só em termos econômicos e técnicos, como também culturais. Os agentes hegemônicos da globalização, ao se instalarem num determinado lugar, que pode ser um Estado-nação, precisam levar em conta essa diferenciação e as particularidades, sob pena de não obterem êxito no empreendimento.

Isso significa que o lugar também é importante no mundo atual, ao contrário da radicalização de considerá-lo insuficiente para o esclarecer e resolver os problemas do espaço em que vivemos. É certo também que ele não soluciona tudo, mas é uma das dimensões da realidade. Portanto, não se deve buscar a solução dos problemas atuais apenas pela via da escala local ou da escala global.

\section{Políticas regionais: tipologias, natureza e alcances}

No contexto brasileiro, há uma confusão entre público e estatal. Muitos consideram que tais noções correspondem à mesma coisa, e isso não é verdadeiro. Um exemplo cabal é a atuação do terceiro setor. Cada 
vez mais ações de interesse público e de natureza coletiva são levadas a cabo por organizações não governamentais (portanto, não estatais) e pelos movimentos sociais, tendo ou não o Estado como parceiro (isso, contudo, não pode ser argumento para deixar o Estado de fora de muitas responsabilidades em que ele é absolutamente fundamental). Só para deixar bem claro, ao contrário do que é estatal, a noção de público nem sempre é aplicada apenas ao Estado.

As políticas públicas são ações elaboradas no âmbito do Estado, mas podem ter sua execução feita por ele de forma total ou apenas parcialmente. A perspectiva aqui adotada é a multicêntrica (Secchi, 2010), que considera não só o Estado, mas também as organizações privadas, não governamentais e organismos multilaterais como protagonistas de políticas públicas. Contudo, entende-se que as políticas regionais de grande envergadura dependem do Estado. Em termos urbanos e regionais, é ele que tem o poder de direcionar grande aporte de recursos para desenvolver regiões deprimidas e gerar novas alternativas de desenvolvimento ou de potencializar ainda mais as regiões modernizadas.

Há uma distinção entre as políticas públicas federais e nacionais, as quais aparentemente são a mesma coisa e, na verdade, não o são. As políticas federais são aquelas implementadas no âmbito do governo federal e somente abarcam a esfera federal.

As políticas públicas nacionais, por sua vez, são levadas a cabo tanto pelo governo federal, como também pelos governos estaduais e municipais, tendo amplo alcance do ponto de vista da sociedade e do território nacional. A universalização da política de saúde, ocorrida com a Constituição de 1988, que instituiu o Sistema Unificado de Saúde (SUS), é um caso típico de política pública nacional, pois União, estados e municípios têm cada um o seu papel e agem de forma integrada.

Outro aspecto importante refere-se a políticas regionais com objetivos de reduzir as desigualdades regionais e as que se destinam a aumentar a competitividade de determinados territórios. Esse é o caso das políticas explicitamente voltadas para as áreas econômicas mais competitivas, a exemplo de tecnopolos. Isso pode contribuir para incrementar a economia de uma determinada região, em detrimento das demais. Essas mesmas políticas de fundo muito mais territorial do que de coesão socioespacial promovem o crescimento econômico de uma região, 
mas podem, em contrapartida, alimentar as desigualdades regionais, pois o que está em jogo é a competição. Já nas políticas regionais, voltadas para a geração de coesão socioespacial, o objetivo principal é promover um padrão de desenvolvimento que leve à redução das desigualdades regionais.

Uma vez que, direta e indiretamente, fazemos referência ao conceito de desenvolvimento, é necessário, então, deixar claro qual ou que tipo de desenvolvimento é considerado aqui. Optamos por uma compreensão mais ampla, que não abarque apenas o viés econômico, como o crescimento da produção industrial, o aumento das exportações, a mecanização do campo ou o crescimento do PIB, dentre outros aspectos tão recorrentes. Tomando o termo desenvolvimento em sentido mais amplo e numa perspectiva crítica, Souza (2003) faz a seguinte reflexão:

\begin{abstract}
Na minha convicção, o desenvolvimento é, nos seus termos mais simples, um processo de mudanças para melhor, um processo incessante de busca de mais justiça social e de melhor qualidade de vida para o maior número possível de pessoas - e isso exige, tanto em matéria de análise de problemas quanto de formulação de estratégias para a superação dos problemas, não somente a consideração das várias dimensões que compõem as relações sociais, mas também uma visão de como essas relações se concretizam no espaço. (Souza 2003, p. 100).
\end{abstract}

À luz do entendimento do autor acima, pode-se falar em desenvolvimento socioespacial, pois a melhoria da qualidade de vida e a busca de maior justiça social têm uma clara dimensão espacial. As fortes desigualdades regionais que caracterizam o território brasileiro poderão ser minimizadas mediante promoção de políticas regionais capazes de induzir o desenvolvimento socioespacial.

É importante ressaltar que há aqui uma preocupação de estabelecer uma correlação entre tais conceitos, uma vez que existe o entendimento de que o Estado, e com ele as políticas regionais, é um agente indispensável para o desenvolvimento nacional, a despeito da globalização e dos acordos que têm levado à formação de blocos supranacionais, como a União Europeia e o Mercosul. 
Tratando ainda da dimensão espacial do desenvolvimento, também há uma distinção entre políticas sociais e políticas regionais. As políticas sociais não têm, obrigatoriamente, o objetivo da coesão socioespacial. Desta feita, o desenvolvimento regional só pode ser vislumbrado diante da criação da coesão e logo pela via da efetiva implementação de políticas regionais.

Pelo que foi apresentado até aqui, pode-se afirmar que o SUS deve ser entendido tanto como uma política nacional como também social. Todavia, as políticas públicas nacionais nem sempre estão imbricadas nas políticas sociais. Só para deixar bem clara essa distinção, embora sociedade e natureza sejam instâncias inseparáveis: numa perspectiva crítica de compreensão do meio ambiente, uma política nacional ambiental nem sempre assume um caráter explícito de política social.

As políticas regionais podem ter um caráter explícito ou implícito, dependendo dos seus objetivos e de seus efeitos diretos e indiretos. Elas são explícitas quando têm efeito direto na solução parcial ou total de um determinado problema regional, ou seja, são implementadas de forma deliberada para solucionar este ou aquele problema. Assim, a qualidade de explícita ocorre quando a política tem um efeito direto sobre o problema para o qual foi elaborada, formulada e executada. Por exemplo, a construção de açudes pelo Departamento Nacional de Obras contra as Secas (DNOCS) pode ser considerada como uma política pública explícita de redução dos efeitos da seca no domínio semiárido do Nordeste brasileiro.

As políticas públicas têm um caráter implícito quando de forma indireta contribuem para minimizar algum problema regional. Por exemplo, para ser financiada, toda política pública precisa ter objetivos claros e bem definidos (do contrário ela não é aprovada, pois significaria desperdício do dinheiro público), pode-se deduzir que, sob determinado ponto de vista, toda ela, a priori, tem um caráter explícito, ou seja, é formulada para resolver um ou alguns problemas determinados. Todavia, indiretamente, ela também pode contribuir para reduzir outros problemas regionais, residindo aí, sua qualidade de implícita.

A expansão e a interiorização da rede federal de educação básica, técnica e tecnológica do governo federal, por exemplo, podem ser compreendidas como uma política pública explícita na área da educação, 
mas não é só isso, uma vez que podem, também, serem consideradas como uma política pública regional implícita. Ao levar unidades federais de ensino para lugares afastados do interior brasileiro, alguns deles muito distantes das áreas de maior dinamismo econômico e urbano, onde é bastante improvável que o mercado se interesse em investir, dada a enorme dificuldade de obtenção de lucro, o Estado está, implicitamente, induzindo o desenvolvimento regional.

Muitas vezes, diante de dificuldades de aprovação no Congresso Nacional de uma política pública explícita para resolver esse ou aquele problema, o governo federal utiliza-ze de outras políticas para atingir, ainda que de forma parcial, os objetivos daquela não implementada oficialmente.

Para entender melhor a natureza das políticas regionais, a figura 1 mostra três situações em que elas se inscrevem. Em geral, as políticas que estão voltadas para reduzir as desigualdades regionais têm um caráter implícito. Isso ocorre porque a solução de um problema dessa magnitude dificilmente ocorre no âmbito de uma única política pública ou apenas pela ação do Estado.

As desigualdades sociais são resultantes de um longo processo histórico e estão ligadas a inúmeros problemas, como a concentração fundiária, o baixo nível de escolaridade, a expansão da estrutura produtiva, a expansão do sistema público de saúde, dentre tantas outras questões que não podem, sob hipótese alguma, serem sanadas por apenas uma política governamental.

Do ponto de vista estritamente regional, toda política pública "regional" é de natureza explícita, conforme está evidenciado ao centro da figura acima. Neste caso, o projeto de interligação de bacias no Nordeste setentrional, através da transposição do rio São Francisco, é parte de uma política explícita de desenvolvimento regional, ou ao menos de tentativa de desenvolvimento regional, para não adotar aqui um tom profético num assunto considerado controvertido. Reitera-se, aqui, que a diferença fundamental entre as políticas regionais é o caráter de coesão socioespacial, gerado por umas, e de competição socioespacial, gerado por outras. 
Figura 1 - Natureza das políticas regionais

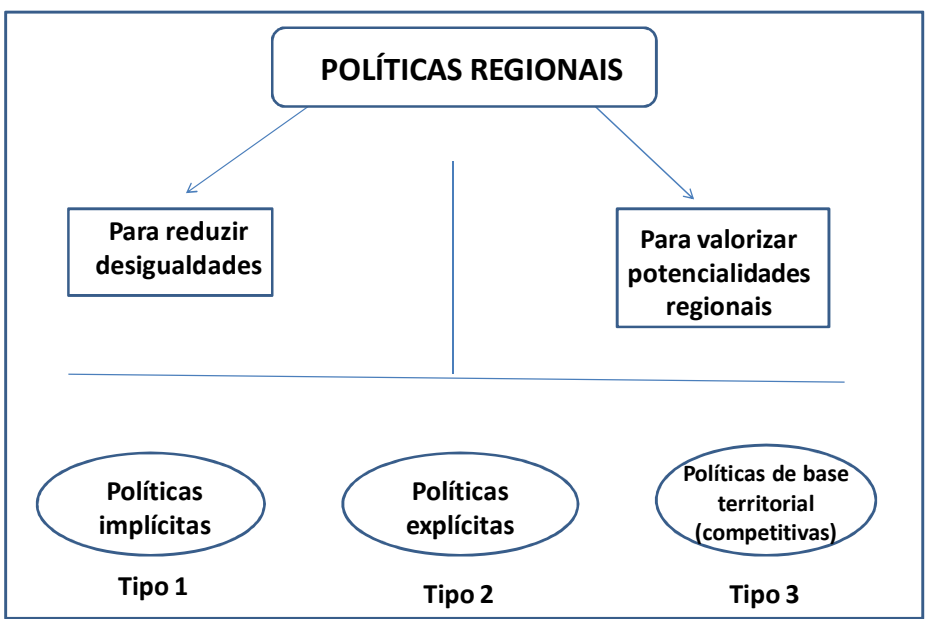

Fonte: Adaptado de material gentilmente cedido pela $\operatorname{Prof}^{\mathrm{a}} \mathrm{Dr}^{\mathrm{a}}$ Tânia Bacelar de Araújo.

Quando o Estado tem o objetivo de estimular ainda mais as potencialidades regionais, geralmente o faz por intermédio de políticas de base territorial, com ênfase na competitividade. Essa modalidade de política também é importante, pois algumas regiões do território nacional, mesmo bastante modernizadas, necessitam do apoio do Estado para tornálas ainda mais competitivas.

Esse é o caso de regiões muito dinâmicas do ponto de vista econômico, como o Vale do Paraíba, na cidade-região formada pela Região Metropolitana de São Paulo e seus principais eixos urbano-industriais, conforme discutido anteriormente. A área urbana de São José dos Campos (SP) é um importante tecnopolo no segmento da indústria aeronáutica e da pesquisa aeroespacial. Diante da globalização e da competitividade internacional, esse tecnopolo necessita de intervenções do Estado para inseri-lo de forma ainda mais competitiva na economia global.

É preciso apenas reiterar que esse não é o único papel do Estado, como fica implícito no discurso neoliberal. É tarefa primordial do Estado promover políticas públicas de desenvolvimento nacional e, como já foi 
dito, o desenvolvimento autêntico perpassa pela melhoria da qualidade de vida e pela busca de equidade social. Atingir, gradativamente, tais objetivos deve ser uma busca permanente das políticas públicas, sem desconsiderar o papel da iniciativa privada e das ações do terceiro setor.

A questão da descentralização tem sido apontada como uma importante saída para o alcance de respostas a muitos problemas brasileiros. Nesse sentido, Araújo (2000) trabalha com a tese da descentralização coordenada. Isso significa que num país tão extenso, heterogêneo e desigual social e economicamente como o Brasil, é preciso que haja uma descentralização. Contudo, é levantado o seguinte questionamento: quem coordena? A esse respeito, a autora adverte: "Para o conjunto do país, quem tem grande capacidade de articulação e coordenação é o governo federal. E quando o governo federal simplesmente sai do caminho, abre espaço para a estratégia da atomização, da descentralização atomizada." (Araújo, 2000, p. 284).

A autora, inclusive, chama a atenção para os riscos de que essa atomização resulte em interferência de atores externos, de forma desconectada ao conjunto de problemas que afetam a região o ou país como um todo. Levada ao extremo, a municipalização desemboca na atomização, que não é suficiente para apontar alternativas de longo prazo para os grandes problemas regionais. Cabe, então, ao governo federal exercer a descentralização coordenada, sob pena de "não haver quem defenda o ponto de vista do país" (Araújo, 2000, p. 284).

Não se pode perder de vista o fato de o Brasil ser continental em termos de extensão territorial, como também muito diverso e heterogêneo. As políticas públicas não devem ter uma visão centralizadora, isto é, virem de cima para baixo.

A despeito dessa tradição centralizadora do Estado brasileiro, há, atualmente, uma proposta de descentralização que parte da sociedade brasileira, pela via do terceiro setor. Há, inclusive, uma postura francamente favorável ao aperfeiçoamento dos mecanismos democráticos e de políticas sociais, o que é muito importante para o enfrentamento dos desafios brasileiros. 


\section{Considerações finais}

A abordagem geográfica da região continua sendo ferramenta teórica fundamental para o entendimento da realidade atual. A despeito da tendência à homogeneização, gerada pela globalização, e da frequente recorrência às escalas global e local, constata-se que é imprescindível ler o mundo todo, ou algumas partes dele, sob o enfoque multiescalar.

Nesse percurso, a escala regional ou, melhor dizendo, as escalas regionais, constituem ponto chave para a compreensão da multiplicidade de contextos que caracterizam a realidade nacional, sobretudo num país de dimensões continentais e muito desigual e heterogêneo como o Brasil, conforme discutido ao longo deste artigo.

Dadas essas características, a execução de políticas regionais é um grande desafio para a gestão pública no Brasil. A dificuldade começa mesmo em tentarmos estabelecer os limites regionais, pois eles devem ser entendidos muito mais como o ponto de chegada do que como o ponto de partida para qualquer política pública. Assim, a despeito de se falar de um Nordeste, há vários Nordestes, cada um com problemas e potencialidades específicos.

Como bem recomendam alguns autores analisados, recorre-se de forma exagerada aos localismos, ao mesmo tempo em que as escalas regionais e, com elas, as políticas regionais tornam-se pouco sedutoras. A excessiva municipalização gera descentralização atomizada e configura um problema por não tratar de problemas nacionais como verdadeiramente nacionais.

Foi apontado que também não se deve desprezar a dimensão local, ou saber local, como bem ressaltou Becker (2010), referindo-se às políticas para a Amazônia, com o intuito de identificar e compreender as particularidades locais nesse país plural. As várias escalas são importantes e necessárias, tendo-se o cuidado de evitar tomá-las de forma isolada, em sentido único e absoluto.

Se se considerar o nível macrorregional, fica patente que uma das dificuldades para a promoção de políticas macrorregionais reside no fato de não haver representação parlamentar nem arrecadação fiscal nesse âmbito, sobretudo no contexto atual de enfraquecimento das agências 
estatais de planejamento regional, quer no âmbito metropolitano, quer no âmbito macrorregional brasileiro.

As macrorregiões, muitas vezes, ficam fora de um corte específico das políticas públicas explícitas. No que se refere às regiões metropolitanas, a situação agravou-se com a falta de dotação orçamentária pelos órgãos de planejamento, a exemplo da CONDEPE/FIDEM, na Região Metropolitana do Recife.

A autonomia conquistada pelos municípios como entes federativos não é suficiente, pois grande parte dos problemas dos municípios das regiões metropolitanas é comum a toda mancha urbana e, por vezes, estende-se por áreas rurais. Esse problema é mais um convite à análise e à formulação de políticas que privilegiem escalas regionais específicas, como a metropolitana.

Observa-se que emergem, no contexto atual, inúmeras possibilidades de interlocução entre o Estado e a sociedade civil organizada. Nesse sentido, a análise regional deve levar em conta o papel das empresas privadas. Mas como as ações do capital são alimentadas inexoravelmente pela lógica do lucro, cabe ao Estado focar suas políticas regionais para áreas onde também o mercado não tem interesse, com o intuito de criar alternativas de desenvolvimento para as regiões em que o mercado não chega ou não quer chegar, viabilizando assim uma maior coesão nacional.

Por fim, toda política regional deriva de uma prévia e detalhada análise regional. Essa, conforme exposto ao longo deste trabalho, deve pautar-se numa abordagem multiescalar e abarcar elementos multidimensionais, como aspectos históricos, físico-territoriais, econômicos, socioculturais, psicossociais, político-institucionais, dentre outros, além do uso de fontes e dados primários e secundários. É necessário, ainda, que o diagnóstico dessa análise contemple as necessidades, os desafios e, também, aponte as possíveis tendências para o desenvolvimento regional. Trata-se de uma tarefa árdua, porém extremamente necessária e oportuna. 
REGIÃO E ESCALA REGIONAL: OS IMPASSES PARA A IMPLEMENTAÇÃO DE POLÍTICAS REGIONAIS NO BRASIL ATUAL

Resumo: O presente artigo faz uma abordagem teórica sobre o tema região e políticas regionais, tratando criticamente a relativa perda de visibilidade da escala regional no contexto atual de elaboração de políticas públicas pelo Estado brasileiro. Nesse sentido, critica a ideologia neoliberal que preconiza o Estado mínimo, o qual dá maior visibilidade às escalas global e local, em detrimento da escala nacional e das políticas regionais. A região é discutida em termos teórico-conceituais, apontando alguns elementos de distintas abordagens, a exemplo das perspectivas analíticas neomarxista e neoestruturalista. No âmbito da Geografia, muitas pesquisas que vêm sendo produzidas apóiam-se nos conceitos de território e lugar, mais relacionados à escala local, e poucos são os estudos que versam sobre a temática propriamente regional. O problema essencial é que no período atual, marcado por uma acentuada crise fiscal, o Estado dispõe de poucas condições para grandes investimentos em políticas regionais. $\mathrm{O}$ ponto de vista aqui defendido é que tal realidade compromete o desenvolvimento nacional, uma vez que as políticas regionais são efetivamente geradoras de coesão do espaço nacional e, por isso, são essenciais para a construção de um sólido projeto de nação. Por fim, é feita uma abordagem sobre as tipologias de políticas públicas, destacando distinções conceituais entre política regional e política territorial, bem como entre política social e política regional. Ao tratar dessas tipologias, o artigo procura apontar seus alcances e possibilidades de ação.

Palavras-chave: região, scala regional, políticas públicas regionais.

\begin{tabular}{|c|c|c|c|}
\hline REGION & REGIONAL & SCALE: & DIFFICULTIES \\
\hline IMPLEMENTATION & $\mathrm{OF}$ & REGIONAL & POLITICS \\
\hline
\end{tabular}

Abstract: This article brings a theoretical approach about the region theme and regional politics, critically approaching the relative loss of visibility of the regional scale in the current context of public politics elaboration by the Brazilian State. Therefore, it criticizes the neoliberal ideology that recommends the minimum State, which emphasizes the global and local scales instead of the national scale and the regional politics. The region is discussed in theoretic-conceptual terms, highlighting some aspects of different approaches, like the neo-Marxist and neo-Structural analytical 
perspectives. In the Geography area, many researches that have been done support the territory and place concepts which are related to the local scale, and only a few studies are developed about the regional thematic itself. The essential problem is that, in the current time, noticeable by severe fiscal crisis, the State can't afford many great investments in regional politics. The point of view supported in this paper defends that this reality undermines the national development, since the regional politics effectively create cohesion of the national space and because of that they are extremely important for the construction of a solid nation project. Finally, it is also done, in this paper, an approach about public politics typology, highlighting conceptual distinctions between regional politics and territorial politics, as well as social politics and regional politics. By discussing these typologies, this article tries to point out their reaches and action possibilities.

Keywords: region; regional scale; regional public politics.

\section{BIBLIOGRAFIA}

ALBUQUERQUE JÚNIOR, D. M. (2001). A invenção do Nordeste e outras artes. $2^{\mathrm{a}}$ ed. Recife: FJN / Editora Massangana; São Paulo: Cortez. ALLEN, J.; MASSEY, D. e COCHRANE, A. (1998). Rethinking the region. Londres: Routledge.

ARAÚJO, T. B. (2000). Ensaios sobre o desenvolvimento brasileiro: heranças e urgências. Rio de Janeiro: Revan / Fase.

BECKER, B. (2000). Brasil, Tordesilhas In: SÁ; Alcindo José de;

PONTES, B. M. S. (orgs.). (2010). O Brasil na geopolitica contemporânea. 31-48. Camaragibe (PE): CCS Gráfica e Editora.

BRANDÃO, C. A. (2004). Teorias, estratégias e políticas regionais e urbanas recentes: anotações para uma agenda do desenvolvimento territorializado. Curitiba: Revista Paranaense de Desenvolvimento. (107): 57-76. jul./dez.

CASTELlS, M. (1999). A sociedade em rede. Tradução: Roneide Venâncio Majer. São Paulo: Paz e Terra. 
DINIZ, C. C.; CAMPOLINA, B. (2007). A Região Metropolitana de São Paulo: reestruturação, re-espacialização e novas funções. Santiago do Chile: Eure, (98): 27-43, maio.

HAESBAERT, R. (2005). Morte e vida da região: antigos paradigmas e novas perspectivas... In SPOSITO, Eliseu Savério (org.). Produção do espaço e redefinições regionais: a construção de uma temática. 9-33. Presidente Prudente. UNESP / FCT / GAsPERR.

- (2010). Regional - global: dilemas da região e da regionalização na Geografia contemporânea. Rio de Janeiro: Bertrand Brasil.

OLIVEIRA, F. (1981). Elegia para uma re(li)gião: Sudene, Nordeste Planejamento e conflito de classe. São Paulo: Paz e Terra.

SANTOS, M. (1997a). A natureza do espaço: técnica e tempo, razão e emoção. $2^{\text {a }}$ ed. São Paulo: Hucitec.

. (1997b). Técnica, espaço, tempo: globalização e meio técnicocientifico informacional. $3^{\mathrm{a}}$ ed. São Paulo: Hucitec.

. (2008). Da totalidade ao lugar. São Paulo: Edusp.

SECCHI, Leonardo. 2010. Políticas públicas: conceitos, esquemas de análise, casos práticos. São Paulo: Cengage Learning.

SOUZA, M. L. (2003). ABC do desenvolvimento urbano. Rio de Janeiro: Bertrand Brasil.

TAVARES, H. M. (1997). Complexos de alta tecnologia e reestruturação do espaço. In SANTOS, Milton et al. (orgs.). Fim de século e globalização. 270-284. $3^{\text {a }}$ ed. São Paulo: Hucitec / ANPUR.

Data de submissão: 15/09/2011

Data de aprovação: 21/05/2012 